\title{
DEXMEDETOMIDINE VERSUS ORAL PREGABALIN TO ATTENUATE HEMODYNAMIC RESPONSE TO LARYNGOSCOPY AND OROTRACHEAL INTUBATION: A COMPARATIVE STUDY
}

\section{SOUMYA SAMAL ${ }^{1 *}$, SHASWAT KUMAR PATTNAIK ${ }^{1}$, NIRANJAN SWAIN ${ }^{1}$, SAUBHAGYA KUMAR JENA ${ }^{2}$}

${ }^{1}$ Department of Anesthesiology and Critical Care, Institute of Medical Sciences and Sum Hospital, SOA University, Bhubaneswar, Odissa, India. ${ }^{2}$ Department of Obstetrics and Gynaecology, All India Institute of Medical Sciences, Bhubaneswar, Odissa, India. Email: samalsoumya11@gmail.com

Received: 09 January 2017, Received and Accepted: 22 February 2017

\section{ABSTRACT}

Objectives: The airway instrumentation of direct laryngoscopy and tracheal intubation is powerful noxious stimuli that should be attenuated by appropriate premedication, smooth induction, and rapid intubation. This study compared the efficacy intravenous dexmedetomidine and oral pregabalin premedication for attenuation of hemodynamic pressor response to laryngoscopy and intubation.

Methods: A total of 60 patients of age group 20-50 years scheduled for elective surgeries under general anesthesia with American Society of Anesthesiologists physical Status I and II were divided into two groups each of 30. Group D received intravenous dexmedetomidine $1 \mathrm{mcg} / \mathrm{kg}$ over 10 minutes before induction, and Group P received oral pregabalin $150 \mathrm{mg} 1 \mathrm{hr}$ before intubation. Parameters observed were heart rate (HR) and mean arterial pressure (MAP) at baseline, after induction, immediately after intubation and then 5, 10, 15, and 30 minutes thereafter.

Results: Attenuation of HR in group dexmedetomidine (78.12 $\pm 10.0 /$ minutes) immediately after intubation was statistically significant than group pregabalin $(89.76 \pm 10.45 /$ minutes). MAP significantly $(\mathrm{p}<0.05)$ decreased after intubation with dexmedetomidine. As compared to oral pregabalin, attenuation of HR and MAP was statistically significant till 30 minutes after intubation with intravenous dexmedetomidine.

Conclusion: Intravenous dexmedetomidine $1 \mu \mathrm{g} / \mathrm{kg}$ is more effective than oral pregabalin $150 \mathrm{mg}$ in attenuating hemodynamic response to laryngoscopy and orotracheal intubation.

Keywords: Hemodynamic pressor response, Laryngoscopy, Intubation, Intravenous dexmedetomidine, Oral pregabalin.

(C) 2017 The Authors. Published by Innovare Academic Sciences Pvt Ltd. This is an open access article under the CC BY license (http://creativecommons. org/licenses/by/4. 0/) DOI: http://dx.doi.org/10.22159/ajpcr.2017.v10i5.16988

\section{INTRODUCTION}

Hemodynamic pressor response to laryngoscopy and endotracheal intubation provokes tachycardia and hypertension that can lead to many adverse events in patients with cardiovascular disease [1]

Dexmedetomidine, an imidazole derivative and highly selective $\alpha_{2}$ adrenergic receptor agonist, is being used widely to attenuate hemodynamic responses [2-4]. Pregabalin has analgesic, anticonvulsant, and anxiolytic effects [5,6]. Several studies have demonstrated the efficacy of oral pregabalin on post-operative analgesia and reduction of parenteral analgesics [7-9]. Oral pregabalin attenuates pressor response to laryngoscopy and endotracheal intubation $[10,11]$.

The aim of this study was to compare the efficacy of intravenous dexmedetomidine and oral pregabalin in attenuating the hemodynamic response to laryngoscopy and endotracheal intubation.

\section{METHODS}

The study was conducted after obtaining approval from Institutional Ethical Committee and informed patients consent during the period of July 2014-October 2015. This prospective, randomized, double-blinded controlled study was conducted on 60 patients of age group 20-50 years scheduled for elective surgeries under general anesthesia with American Society of Anesthesiologists (ASA) physical Status I and II. Patients with a history of the cardiac, pulmonary or renal disease, obesity, anticipated difficult intubation, allergic to any anesthetic medication, pregnant and lactating patients and those taking sedatives, hypnotics or antihypertensives were excluded from the study. We also excluded cases where laryngoscopy exceeded 20 seconds or a second attempt was needed. Both patients and observer were totally blind about the groups and medications given.
In the pre-operative room, baseline heart rate (HR) along with systolic, diastolic, and mean arterial blood pressure was recorded. Patients were randomly divided into two groups each of 30 patients by computer-generated random table. Group D received intravenous dexmedetomidine $1 \mathrm{mcg} / \mathrm{kg}$ over 10 minutes before induction, and Group P received oral pregabalin $150 \mathrm{mg} 1 \mathrm{hr}$ before intubation. A crystalloid intravenous fluid was started, and all the patients were premedicated with intravenous ranitidine $(50 \mathrm{mg})$, ondansetron ( $8 \mathrm{mg}$ ), midazolam $(1 \mathrm{mg})$, and glycopyrrolate $(0.2 \mathrm{mg})$. After preoxygenation for 3 minutes with $100 \%$ oxygen, anesthesia was induced with propofol $(2 \mathrm{mg} / \mathrm{kg})$ or in a dose sufficient for loss of verbal commands. The direct laryngoscopy and intubation were facilitated with vecuronium $0.1 \mathrm{mg} / \mathrm{kg}$. Intravenous fentanyl $2 \mu \mathrm{g} / \mathrm{kg}$ was administered 15 minutes after intubation to avoid its effect on hemodynamic response. Anesthesia was maintained with isoflurane and nitrous oxide $60 \%$ in oxygen. Patients were mechanically ventilated to maintain the normocapnia. After completion of surgery, residual neuromuscular block was antagonized with appropriate intravenous doses of neostigmine $(0.05 \mathrm{mg} / \mathrm{kg})$ with glycopyrrolate $(0.01 \mathrm{mg} / \mathrm{kg})$, and extubation was performed when respiration was spontaneous and adequate

Parameters observed were HR and mean arterial pressure (MAP) at baseline, after induction, immediately after intubation and then 5, 10, 15 , and 30 minutes thereafter. Decrease in MAP by more than $20 \%$ from baseline or systolic arterial pressure $<90 \mathrm{~mm} \mathrm{Hg}$ was treated by increasing the intravenous fluid infusion rate or incremental doses of ephedrine $5 \mathrm{mg}$ IV bolus. Decrease in HR $(<50$ beats/minutes) was treated with atropine $0.5 \mathrm{mg}$ IV.

\section{Statistical analysis}

The sample size was calculated by power analysis (power $80 \%$ and $\alpha$ error 0.05 ) from initial pilot studies. The calculated sample size for 
each group was 23 patients. Presuming the dropout rate to be $5 \%$, it was decided to include 30 patients each group. Data were expressed as mean \pm standard deviation and analyzed by Student's t-test and Chi-square test. Probability (p) was considered to be significant if $<0.05$.

\section{RESULTS}

Out of the 60 patients, 30 patients in each group were evaluated and compared (Table 1). Patients demographic profile were similar in both groups. The duration of laryngoscopy and intubation was similar in both groups. No significant difference was found among them with respect to age, sex, weight, ASA grading, duration of laryngoscopy and anesthesia.

Attenuation of HR in group dexmedetomidine $(78.12 \pm 10.0 /$ minutes $)$ immediately after intubation was statistically significant than group pregabalin (89.76 $\pm 10.45 /$ minutes) (Table 2 ). MAP significantly $(\mathrm{p}<0.05)$ decreased after intubation with dexmedetomidine as shown in Table 3. As compared to oral pregabalin, attenuation of HR and MAP was statistically significant till 30 minutes after intubation with intravenous dexmedetomidine. No post-operative respiratory depression, nausea, and vomiting were found, and no other post-operative complication was recorded in any group during our study.

\section{DISCUSSION}

Attenuation of the sympathoadrenal stress response is important especially in high-risk patients [12]. Various methods such as $\alpha$ or $\beta$ adrenergic blockers, opioids, topical or systemic lignocaine are being used to attenuate hemodynamic response [13-15]. Dexmedetomidine possess anxiolytic, sedative, analgesic, and sympatholytic properties. It may be used as premedicant, adjunct to balanced anesthesia as it remarkably reduces the doses of the anesthetic drugs [16]. Pregabalin, (S)-3-(aminomethyl)5 -methylhexonic acid is a new structural, and non-functional analog

Table 1: Demographic profile

\begin{tabular}{lll}
\hline Variables & Group D & Group P \\
\hline Age (years) & $32.2 \pm 12.3$ & $31.5 \pm 11.58$ \\
Weight (kg) & $50.9 \pm 10.7$ & $52.4 \pm 11.4$ \\
Sex (male: female) & $21: 9$ & $18: 12$ \\
ASA Grade I: II & $19: 11$ & $20: 10$ \\
Duration oflaryngoscopy (seconds) & $19.77 \pm 1.5$ & $19.74 \pm 1.6$ \\
\hline
\end{tabular}

ASA: American Society of Anesthesiologists

Table 2: Changes in HR (beats/minutes)

\begin{tabular}{llll}
\hline Time intervals & Group D & Group P & p value \\
\hline Baseline & $86.45 \pm 8.37$ & $85.5 \pm 7.84$ & 0.65 \\
After induction & $80.4 \pm 10.23$ & $84.0 \pm 9.72$ & 0.10 \\
After intubation (minutes) & & & \\
$\quad$ Immediately & $78.12 \pm 10.0$ & $89.76 \pm 10.45$ & 0.00 \\
5 & $75.45 \pm 11.8$ & $86.33 \pm 11.59$ & 0.00 \\
10 & $78.0 \pm 12.45$ & $84.46 \pm 10.37$ & 0.03 \\
15 & $77.4 \pm 11.68$ & $83.85 \pm 9.76$ & 0.02 \\
30 & $74.50 \pm 8.67$ & $77.4 \pm 9.24$ & 0.21 \\
\hline
\end{tabular}

Table 3: Changes in MAP (mm Hg)

\begin{tabular}{llll}
\hline Time intervals & Group D & Group P & p value \\
\hline Baseline & $95.63 \pm 7.92$ & $97.66 \pm 8.56$ & 0.34 \\
After induction & $80.54 \pm 9.79$ & $82.45 \pm 8.74$ & 0.42 \\
After intubation (minutes) & & & \\
$\quad$ Immediately & $88.57 \pm 10.95$ & $94.82 \pm 10.98$ & 0.03 \\
5 & $87.79 \pm 11.47$ & $93.53 \pm 10.53$ & 0.04 \\
10 & $82.0 \pm 12.29$ & $88.67 \pm 10.98$ & 0.03 \\
15 & $82.17 \pm 11.0$ & $88.35 \pm 11.20$ & 0.03 \\
30 & $84.11 \pm 9.34$ & $86.0 \pm 10.65$ & 0.46 \\
\hline
\end{tabular}

MAP: Mean arterial pressure of gamma-aminobutyric acid acts at pre synaptic calcium channels to modulate neurotransmitter release in the central nervous system (CNS) and used as an adjuvant in the treatment of partial seizures, general anxiety disorders, neuropathic pain (1-2). Pregabalin (pree- $\gamma$-lin) binds to the $\alpha_{2}-\delta$ site an auxiliary subunit of voltage-gated calcium channels in the CNS, inhibiting excitatory neurotransmitter release. [17].

In our study, intravenous dexmedetomidine was found to be more effective than oral pregabalin in attenuating hemodynamic response to laryngoscopy and endotracheal intubation. Dexmedetomidine produces hyperpolarization of noradrenergic neurons and suppression of neuronal firing in the locus cerelous that leads to decrease in systemic noradrenalin release and attenuation of sympathoadrenal response during laryngoscopy and intubation [4]. There was statistically significant difference $(\mathrm{p}<0.05)$ inchange of mean HR and MAP between the oral pregabalin and dexmedetomidine group immediately the following intubation. Attenuation of HR and MAP was significant up to 30 minutes after intubation with intravenous dexmedetomidine.

The previous study has shown that oral pregabalin at dose $75 \mathrm{mg}$ was not effective in attenuating pre-operative anxiety and at a dose of $300 \mathrm{mg}$ produced increased level of sedation after surgery [18]. Based on the result of the previous study, the dose of pregabalin was chosen as $150 \mathrm{mg}[10]$.

Chaudhary et al. have shown that oral pregabalin and clonidine have both effectively blunt hemodynamic pressure response to laryngoscopy without prolongation of recovery time and side effects [19]. It is found that intravenous dexmedetomidine is more effective in attenuating the hemodynamic response to laryngoscopy and intubation than other agents $[3,20-22]$.

When assessing techniques to lessen the hemodynamic pressor responses of airway instrumentation, the induction agents may influence the results. We have used propofol as an induction agent, which produces hypotension more than thiopental and bradycardia, which has helped to compensate in part the hemodynamic changes induced due to laryngoscopy and intubation in all patients [23]. The salivary and tracheobronchial mucus secretions necessitate prophylactic administration of intravenous glycopyrrolate.

The limitation of the study was that sedation score and recovery time was not compared.

\section{CONCLUSION}

Intravenous dexmedetomidine $1 \mu \mathrm{g} / \mathrm{kg}$ is more effective than oral pregabalin $150 \mathrm{mg}$ in attenuating hemodynamic response to laryngoscopy and orotracheal intubation.

\section{REFERENCES}

1. Shribman AJ, Smith G, Achola KJ. Cardiovascular and catecholamine responses to laryngoscopy with and without tracheal intubation. Br J Anaesth 1987;59:295-9.

2. Khan ZP, Ferguson CN, Jones RM. Alpha-2 and imidazoline receptor agonists. Their pharmacology and therapeutic role. Anaesthesia 1999;54:146-65.

3. Reddy SV, Balaji D, Ahmed SN. Dexmedetomidine versus esmolol to attenuate the hemodynamic response to laryngoscopy and tracheal intubation: A randomized double-blind clinical study. Int J Appl Basic Med Res 2014;4(2):95-100.

4. Grewal A. Dexmedetomidine: New avenues. J Anaesthesiol Clin Pharmacol 2011:27:297-302.

5. Tippana EM, Hamunen K, Kontinen VK, Kalso E. Do surgical patients benefit from perioperative gabapentin/pregabalin? A systematic review of efficacy and safety. Anesth Anal 2007;104:1545-56.

6. Rose MA, Kam CA. Gabapentin: Pharmacology and its use in pain management. Anaesthesia 2002;57:451-62.

7. Durkin B, Page C, Glass P. Pregabalin for the treatment of postsurgical pain. Expert Opin Pharmacother 2010;11(16):2751-8

8. Ghai A, Gupta M, Hooda S, Singla D, Wadhera R. A randomized 
controlled trial to compare pregabalin with gabapentin for postoperative pain in abdominal hysterectomy. Saudi J Anaesth 2011;5(3):252-7.

9. Kohli M, Murali T, Gupta R, Khan P, Bogra J. Optimization of subarachanoid block by oral pregabalin for hysterectomy. J Anaesthesiol Clin Pharmacol 2011;27(1):101-5.

10. Salman E, Celik C, Candan S. Premedication with single dose pregabalin $150 \mathrm{mg}$ attenuates hemodynamic response to laryngoscopy and endotracheal intubation. Open Access Sci Rep 2012;1:297.

11. Bhandari G, Mitra S, Shahi KN, Rani A, Chauhan A. Pre-emptive use of oral pregabalin attenuates the pressor response of laryngoscopy and endotracheal intubation: A double blinded randomized placebo controlled study. Ann Int Med Dent Res 2016;2(3):110-4

12. Hassan HG, EL-Sharkawy TY, Renk H, Mansour G, Fouda A. Hemodynamic and catecholamine stress responses to laryngoscopy with vs without endotracheal intubation. Acta Anesthesiol Scand 1991;35:442-7.

13. Casati A, Fanelli G, Albertin A, Deni F, Daneilli G, Grifoni F, et al. Small doses of remifentanil or sufentanil for blunting cardiovascular changes induced by tracheal intubation: A double blind comparision. Eur J Anaesthesiol 2001;18:108-12.

14. Singh H, Vichitvejpaisal P, Gaines GY, White PF. Comparative effects of lidocaine, esmolol, and nitroglycerin in modifying the hemodynamic response to laryngoscopy and intubation. J Clin Anesth 1995;7(1):5-8.

15. Arora S, Kulkarni A, Bhargava AK. Attenuation of hemodynamic response to laryngoscopy and orotracheal intubation using intravenous clonidine. J Anaesthesiol Clin Pharmacol 2015;31(1):110-4.

16. Bansal T, Hooda S. Newer drugs in anaesthesia. Int J Pharm Pharm Sci
2012;4(1):668-70

17. Kumar BS, Sinha VR. Natural and synthetic hydrophilic matrices for development of pregabalin extended release tablets. Int J Pharm Pharm Sci 2013;5(3):1-8

18. White PF, Tufanogullari B, Taylor J, Klein K. The effect of pregabalin on preoperative anxiety and sedation levels; A dose ranging study. Anesth Analg 2009;108:1140-5.

19. Chaudhary A, Sanghvi K, Parikh H. Oral premedication with pregabalin and clonidine for hemodynamic stability during laryngoscopy: A comparative study. Int J Basic Clin Pharmacol 2015;4:294-9.

20. Jain V, Chandak A, Ghosh A, Golhar M. Comparison of dexmedetomidine and fentanyl for attenuation of the hemodynamic response to laryngoscopy and tracheal intubation. Ain-Shams J Anaesthesiol 2015;8:236-43.

21. Sarkar A, Tripathi RK, Choubey S, Singh RB, Awasthi S. Comparison of effects of intravenous clonidine and dexmedetomidine for blunting pressor response during laryngoscopy and tracheal intubation: A randomized control study. Anesth Essays Res 2014;8(3):361-6.

22. Gulabani M, Gurha P, Dass P, Kulshreshtha N. Comparative analysis of efficacy of lignocaine $1.5 \mathrm{mg} / \mathrm{kg}$ and two different doses of dexmedetomidine $(0.5 \mu \mathrm{g} / \mathrm{kg}$ and $1 \mu \mathrm{g} / \mathrm{kg})$ in attenuating the hemodynamic pressure response to laryngoscopy and intubation. Anesth Essays Res 2015;9(1):5-14.

23. Rastogi B, Gupta K, Gupta PK, Agarwal S, Jain M, Chauhan H. Oral pregabalin premedication for attenuation of haemodynamic pressor response of airway instrumentation during general anaesthesia: A dose response study. Indian J Anaesth 2012;56:49-54. 